\title{
Business Model Involvement, Adaptive Capacity, and the Triple Bottom Line at the Base of the Pyramid
}

\author{
Ernst Verwaal ${ }^{1} \cdot$ Martin Klein $^{2} \cdot$ Jefferson La Falce ${ }^{3}$
}

Received: 8 September 2020 / Accepted: 26 August 2021 / Published online: 31 August 2021

(c) The Author(s) 2021

\begin{abstract}
Almost two decades ago, Prahalad and Hammond [Harv Bus Rev, 80(9):48-59, 2002] introduced the base/bottom of the pyramid (BOP) approach to profitably serving the poor with business models adapted from developed markets while alleviating poverty. In response to disappointing results and ethical criticism, the BOP approach evolved from a just-for-profit approach with a passive role of the poor to an inclusive development approach that integrates the principles of the triple bottom line. A recent review of the BOP literature [Dembek et al., J Bus Ethics 165(3):365-382, 2020], however, reveals a lack of empirical evidence to support the sustainable BOP approach. In this paper, we specify the assumptions underlying the sustainable BOP approach and test them using structural equation modeling with clustered robust standard errors on a unique dataset of 212 firms. Our findings show that BOP business model involvement and adaptive capacity are significant drivers of the triple bottom line at the BOP; however, business model adaptive capacity does not guarantee an ecologically sustainable performance at the BOP. We find that there is a need for further extension of the ethical foundations of the sustainable BOP approach.
\end{abstract}

Keywords Sustainable base-of-the-pyramid approach · Business model adaptive capacity · Triple bottom line

\section{Introduction}

A growing body of literature has explored business opportunities at what has been referred to as the "bottom- or baseof-the-pyramid" (next BOP) markets, which represent about $40 \%$ of the world population (Sumner et al., 2020). Although some progress has been made to reduce extreme poverty in recent years, the World Bank estimates that the number of people living in extreme poverty could increase to around

Ernst Verwaal

ernst.verwaal@kuleuven.be

Martin Klein

martin.h.klein@gmail.com

Jefferson La Falce

jefferson.falce@fumec.br

1 Faculty of Economics and Business, KU Leuven, Campus Carolus, Hendrick Conscienceplein 8, 2000 Antwerp, Belgium

2 Changeroo, Stadhuisplein 15, 3012 AR Rotterdam, The Netherlands

3 Faculty of Management, FUMEC University, B-2000, Belo Horizonte, Brazil
9\% in 2020 and the number of people living in poverty could increase to around $42 \%$ of the global population (Sumner et al., 2020). Most of the poor live in areas that are sensitive to the consequences of climate change to which the poor are more vulnerable (Arnold \& Williams, 2012), thus, making the prospects for the poor even more grim.

The idea that the profit motive of the private sector can contribute to poverty alleviation can largely be attributed to the belief that fundamental business competences-such as conducting market research, managing value chains, assessing risk, and scaling up operations - are vital not only for business success but also for the sustainable development of those living in poverty (London, 2016; Prahalad, 2009). Private business initiatives can stimulate new investment, growth, and sustainable innovation at the BOP (Prahalad, 2009), thereby, generating positive externalities such as building local capacity, employment opportunities, and increasing choice with products and services adapted to the specific needs of the poor.

However, there are many internal and external barriers to the scalability of BOP business models. Externally, poverty is a highly localized phenomenon (Calton et al., 2013) that requires business models to efficiently adapt to a variety of 
needs and behaviors of the poor. BOP markets suffer from opaque market information, an underdeveloped infrastructure, a lack of professional services, a weak regulatory environment (Prahalad, 2009; Prahalad \& Hammond, 2002), and fragmented markets (Anderson \& Markides, 2007) with high geographic and cultural diversity (Austin et al., 2007). Internally, firms face cognitive and structural barriers to creative and explorative processes needed to adapt products or services to the conditions at the BOP (Halme et al., 2012; Reficco \& Gutiérrez, 2016). Whether internal or external, these barriers interact with the deployment of business models adapted from developed markets giving rise to the disruption of market, social, and environmental conditions at the BOP (Rosenstock et al., 2020). Hence, business models at the BOP must be prepared to respond to unexpected changes, and this makes adaptive capacity critical in scaling business models across the large variety of countries, cultures, and languages of BOP markets (Gutiérrez et al, 2016; Prahalad, 2005; Reficco \& Gutiérrez, 2016). However, few studies have empirically validated if the adaptive capacity of the business model positively influences economic, social, and environmental performance at BOP markets.

Prior BOP research also criticized the BOP approach for the naive assumption that companies only focused on profit would be able to deliver to its promises (Arora \& Romijn, 2012; Chliova \& Ringov, 2017). It is unclear if the poor will benefit from spending on new consumer products or services from money that they need for life necessities. Furthermore, these products and services adapted from developed markets may disrupt social structures and traditions at the BOP (Karnani, 2007) and replace local producers to weaken rather than strengthen the well-being of the poor (Dembek et al. 2019). In response to these criticisms, new iterations of the BOP approach were proposed. Dembek et al. (2020) found in their systematic review of the BOP literature that the BOP approach has evolved from profit-driven selling of goods and services to the poor as consumers (BOP 1.0) (Prahalad $\&$ Hart, 2002) to including the poor as business partners in the value chain (BOP 2.0) (Simanis \& Hart, 2008). However, this second reiteration of the BOP approach also received criticism. Inclusion of the BOP as partners in the value chain assumes that there are institutional mechanisms that protect the poor. Mair et al. (2012) argue that sustainable BOP initiatives are more likely to fail due to institutional voids that hinder the development of inclusive markets. Private firms that are only focused on the maximization of profits are therefore more likely to reinforce social and economic inequalities at the BOP.

This criticism led to a third reiteration of the BOP approach that integrates the principles of the triple bottom line (Elkington, 1997) into a sustainable BOP approach (BOP 3.0) (Cañeque \& Hart, 2015; Chmielewski et al., 2020; London, 2016). Originally, the BOP approach rejected the ethical motivation of BOP projects because this could undermine the focus on the core business competencies that are expected to produce positive externalities for the poor (Simanis \& Milstein, 2012). Other scholars suggest that firms that simultaneously are committed to commercial and (ethical) development goals may prioritize their commercial logic over their development logic and this may also explain why they fail to produce the expected positive externalities for the poor (Arora \& Romijn, 2012; Chliova \& Ringov, 2017; Karnani, 2007). Hybrid organizations may support adaptive capacity of the business model as competing organizational goals create uncertainty and ambiguity that enables change and stimulates the search for new opportunities (Smith \& Besharov, 2019). However, Battilana and Dorado (2010) show that hybrid organizations that combine both sustainable development and commercial logics at the BOP experience significant conflict between these logics because hybrid organizations do not have an explicit protocol that explains how to prioritize commercial, social, and environmental objectives at the BOP (Alexius \& Furusten, 2020; Denis et al., 2015). The tension between economic development and ecology may particularly apply to the development at the BOP. Hahn (2009) shows that there may be a moral dilemma between intra- and intergenerational justice as economic development at the BOP without regard for the ecological environment may violate the rights of future generations. Due to its size, the unsustainable economic development of the BOP could cause unprecedented global environmental degradation (London \& Hart, 2011) to which the poor are also most vulnerable (Arnold \& Williams, 2012).

Thus, there is a lack of empirical evidence to support the sustainable BOP approach and in the present study, we aim to inform the BOP literature on the capacity of the sustainable BOP 3.0 approach to address the competing demands of the triple bottom line at the BOP. Specifically, we seek to address the following research question: Can BOP business model involvement and adaptive capacity of firms that simultaneously pursue profit and development goals contribute to the triple bottom line at the BOP? The evidence provided by our paper shows that the sustainable BOP approach works with respect to the social impact and financial performance of the business model but does not support a positive environmental impact. This finding challenges a key assumption of BOP 3.0 that companies at the BOP with an explicit motivation for sustainable development will realize an ecologically sustainable performance. These findings highlight the need for further explication of the ethical foundations of the BOP approach.

In the remainder of the paper, we first specify the assumptions underlying the sustainable BOP approach and their consequences for business model adaptive capacity and the triple bottom line. Next, we empirically test the proposed relationships using latent variable SEM estimation with 
clustered robust standard errors on 212 firms that simultaneously pursue economic and development goals in 37 countries at the BOP. We conclude with a discussion of the implications of our results for the further development of a sustainable BOP approach, limitations, and suggestions for further research.

\section{Conceptual Development}

\section{Business Model Involvement and Adaptive Capacity at the BOP}

Companies from developed economies are used to developing new products and services with sufficient resources and advanced technology, however, low-income markets have their own unique logic and require producers to minimize the use of resources (Sutter et al., 2014) and the level of complexity (Garrette \& Karnani, 2010; Knorringa et al., 2016). BOP producers may be more experienced in applying this logic because they are more expedient with resource scarcity and frugal innovation than firms from higher income markets. In addition, BOP producers may also be more effective managers of the reconfiguration of resources because they are familiar with local culture and traditions and have access to local social networks (Berger et al., 2011; Calton et al., 2013). This is particularly important at the BOP because the high geographic and cultural diversity of BOP markets (Austin et al., 2007) combined with the low purchasing power of the poor makes this local knowledge critical to adapt to the heterogeneous conditions of the poor with reasonable efficiency (Reficco \& Gutiérrez, 2016).

Thus, the conditions at the BOP require a high level of adaptive capacity because there is a high variability in consumer preferences, local capacity, and infrastructure. This necessitates firms to flexibly adapt marketing, logistics, and operations to a large variety of different and often unpredictable circumstances (Dawar \& Chattopadhyay, 2002; Tashman \& Marano, 2009). The poor infrastructure (Arnold \& Quelch, 1998; Doh \& Ramamurti, 2003) and limited availability of communication channels (Arnold \& Quelch, 1998) makes adaptation towards individual circumstances unassailable. "Poverty is a localized phenomenon that affects individuals specifically and differently in different locales" (Calton et al., 2013, p. 730). Furthermore, the interaction of the business model with the BOP business environment can further increase the unpredictability of the economic, social, and environmental conditions at the BOP (Rosenstock et al., 2020).

To build an adaptive capacity at the BOP, firms have been guided to involve BOP producers, customers, and suppliers (London, 2016; Simanis et al., 2008) in the value chain to develop a "native capacity" (Hart \& London, 2005). This is central to the second iteration of the BOP approach (BOP 2.0) that shifted the BOP 1.0 approach of selling to the poor as passive consumers to co-creation with the poor as active business partners (Simanis \& Hart, 2008). Involvement of local value chain partners from the BOP gives access to different mental models and knowledge that enhances coordination efficiency and adaptivity (Reficco \& Gutiérrez, 2016). Firms increasingly recognize that involvement of the BOP actors in the value chain can help to internalize a broader range of ethical values by practical discourse with the poor (Habermas, 1990). This allows them to address economic as well as social and environmental challenges at the BOP (Hart \& Milstein, 2003; Lashitew et al., 2020; Santos \& Laczniak, 2009). Thus, we hypothesize:

Hypothesis 1 Business model involvement of (a) BOP producers, (b) BOP suppliers, and (c) BOP consumers is positively related to the adaptive capacity of the business model at the BOP.

\section{Business Model Adaptive Capacity and the Triple Bottom Line at the BOP}

Business model adaptive capacity allows a firm to maintain fit with its environment by modifying its business model in response to uncertain conditions (Teece, 2018). The adaptive capacity of the business model expresses the capacity of the business model to cope with uncertainty and unpredictable variations in the business environment (Morgan, 1997; Parsons, 1964). Adaptation seeks to find optimal fit to existing contingencies, while adaptive capacity refers to the ability to cope with unknown future circumstances (Nohria \& Gulati, 1996; Nonaka, 1994). Thus, adaptive capacity can help a firm to deal with the uncertain economic, social, and environmental challenges (Foster \& Heeks, 2013).

The large number of external and internal barriers combined with low purchasing power of the poor makes adaptive capacity critical in scaling business models at BOP markets (Gutiérrez et al., 2016; Reficco \& Gutiérrez, 2016). In the BOP context, environmental uncertainty/heterogeneity and personal- and context-driven adaptation are important (Calton et al., 2013; Dawar \& Chattopadhyay, 2002; Sutter et al., 2014). These factors all challenge the firm to create fit with the BOP environment. Most people at the BOP live in developing and emerging countries where market conditions can change rapidly due to economic and political instability (Jenkins \& Thomas, 2002). Moreover, these markets display high heterogeneity in cultural orientations, traditions, religious beliefs (Letelier et al., 2003) and infrastructure with vast differences between isolated rural areas and large, densely populated cities (Dawar \& Chattopadhyay, 2002; Globerman \& Shapiro, 2003). Furthermore, natural resources at the BOP are scarce and expensive, and therefore, companies at the BOP need 
adaptive capacity to develop creative and environmentally sustainable solutions (Prahalad, 2009, p. 57). In BOP markets there are many examples of such specific adaptations to unique customer requirements such as aqua-aero water systems and room temperature storage of dairy products, which require substantial scale to be profitable.

The adaptations needed at the BOP are not only financial but also include social and environmental components such as contributions to employment opportunities, the development of public services, and the enhancement of access to primary life necessities (London \& Hart, 2004). The low living standards at the BOP makes people's needs predominantly social in nature (Banerjee \& Duflo, 2007; Hammond et al., 2007). Thus, fitting the needs of the stakeholders at the BOP and building upon the strengths of its social networks requires adaptation to social norms at the BOP.

The natural environment is a common concern among the people at the BOP (Hart, 1997, 2005; Prahalad, 2005) because the environment is a daily lifeline for the poor. Produces from woodlands, fisheries, and small-scale agriculture are a fallback when other sources of employment falter. "As subsistence and small-scale farmers and fishermen, they [the BOP] are uniquely vulnerable to destruction of the natural resources they depend on" (Hammond et al., 2007, p. 5). Furthermore, due to its vast size, even a small increase in demand at the BOP can lead to serious environmental problems (Hart \& Milstein, 2005). Environmental adaptations may therefore be of crucial importance to stakeholders in the BOP environment (Hart, 1997, 2005).

Due to the heterogeneity and uncertainties of economic, social, and environmental challenges at the BOP environment, companies need to design business models with high adaptive capacity to successfully scale the business model across a wide variety of countries, cultures, and languages (Immelt et al., 2009; Prahalad, 2009; Prahalad \& Hammond, 2002). Furthermore, the deployment of BOP business models adapted from developed markets may also give rise to unexpected disruption of economic, social, and environmental conditions at BOP markets (Rosenstock et al., 2020) to which the organization needs to respond. This leads to the expectation that business model adaptive capacity supports value propositions with positive social, environmental, and financial performance in BOP markets. Therefore, we hypothesize:

Hypothesis 2 Business model adaptive capacity is positively related to (a) social impact, (b) environmental impact, and (c) financial performance.

\section{Social Impact, Environmental Impact, and Financial Performance at the BOP}

Corporate social responsibility (CSR) research indicates that social and environmental impact are positively related to financial performance (Margolis \& Walsh, 2003; Orlitzky et al., 2003). There are several reasons why this win-win condition may also apply to the BOP context. First, positive social impact is considered important by stakeholders at the BOP (Immelt et al., 2009; Lashitew et al., 2020). The poor tend to be distrustful towards commercial companies (Karnani, 2007) and a positive social impact can increase trust among the poor, which may in turn lower transaction and agency costs at the BOP (Jones, 1995).

Second, the BOP literature is aware of the possible negative effects of economic growth at the BOP for the ecological environment (Arnold \& Williams, 2012; Hahn, 2009; London \& Hart, 2011). However, there are several arguments for a positive relationship between environmental and financial value at the BOP. Natural resources available from fishing or small-scale farming are an important source of income for the rural poor, which makes them vulnerable to environmental degradation (Arnold \& Williams, 2012; Hammond et al., 2007). Furthermore, positive environmental impact would require fewer natural resources such as water, energy, and transportation, which are scarce and expensive at the BOP. The poor "spend a disproportionate amount of their income on expensive inefficient sources such as batteries, oil and candles" (Prahalad, 2009, p. 359). Thus, providing more efficient products for the poor improves their welfare and has a positive environmental impact. The same applies to business processes where the firms' improved cost efficiency can reduce the need for natural resources, which ultimately contribute to firms' environmental and financial performance (Hart, 2005; Porter, 1995).

Limited natural resources make it difficult to imagine including the BOP in the formal market system using the same resource-intensive business models currently employed in high-income markets. Because of potential environmental problems, limited natural resources, the widening gap between poor and rich, and the intrinsic value of nature, economic growth at the BOP that increases environmental degradation is likely to encounter substantial resistance. Even though the regulatory environment is generally weak at the BOP, we can expect that regulators at the BOP would like to avoid a strong environmental footprint from economic development at the BOP because this further increases the problems of resource scarcity and requires costly environmental restoration initiatives. Thus, despite the possible tension between economic growth and sustainability at the BOP, there are strong arguments to support the positive relationship between social and environmental impact and the financial performance at the BOP. This suggests our final hypothesis:

Hypothesis 3 (a) Social impact and (b) environmental impact have a positive relationship with firm financial performance. 
Figure 1 presents the conceptual model that summarizes the proposed theoretical relationships reflecting our interpretation of the main assumptions underlying the sustainable BOP approach. In the next section of the paper, we discuss the data and methods used to test the relationships of the conceptual model.

\section{Data and Methods}

The research setting of this study is the BOP where for-profit and non-philanthropic organizations that build inclusive business models with a focus on the BOP as customers, producers, and/or suppliers. The original BOP approach focused on just-for-profit organizations and rejected ethical and CSR motivation because, in their view, this could distract from the effective application of core business competences (Simanis \& Milstein, 2012). In response to disappointing results and ethical criticism on the BOP approach (Arora \& Romijn, 2012; Chliova \& Ringov, 2017; Karnani, 2007), the third iteration of the BOP approach (BOP 3.0) added the explicit motivation for sustainable development and the triple-bottom-line perspective (Cañeque \& Hart, 2015; Chmielewski et al., 2020; Dembek et al., 2020). With our sampling procedure, we followed this approach assuming that the most recent reiteration of the BOP approach is the standard BOP approach. However, as indicated by reviewers, the debate on the profit motive is not yet concluded and we added an explanation of the limitation of the sample to hybrid firms.
To ensure that the business model was a central construct, we selected organizations with 10 employees or more. The respondents had a senior management position within the organization. We requested 15 organizations with extensive networks at the BOP to provide us with contact information of organizations fitting the above criteria. The variety of these organizations produced a broad and representative sample of respondents of which $39 \%$ are active at the BOP in Africa, 41\% Latin America, 9\% from Asia, and 11\% on other continents. Of the 718 organizations selected for this study, we received 214 usable questionnaires. The five industries with the largest contribution to the sample are trading/wholesale (10.56\%), retail (6.57\%), manufacture/ repair (19.01\%), farming/fishing/forestry $(9.86 \%)$, and financial services $(11.27 \%)$. We tested the representativeness of the sample by comparing the sample with the population structure reported by Hammond et al. (2007) and we found no significant differences. We performed the test proposed by Armstrong and Overton (1977) to evaluate possible nonresponse bias by comparing early and late respondents. The non-response test assumes that late respondents are more similar to non-respondents than early respondents. We found no significant difference between early and late respondents with respect to firm age $(p<0.92)$, sales growth $(p<0.91)$, profit margin $(p<0.94)$, and net profit $(p<0.24)$ indicating that non-response bias is not a significant problem in our sample.

We surveyed additional members of nine randomly selected responding firms to examine issues associated with single-informant data. For each variable, we calculated an

\section{BOP value chain involvement \\ Business model adaptive capacity \\ Business model social Business model and environmental Impact financial Performance}

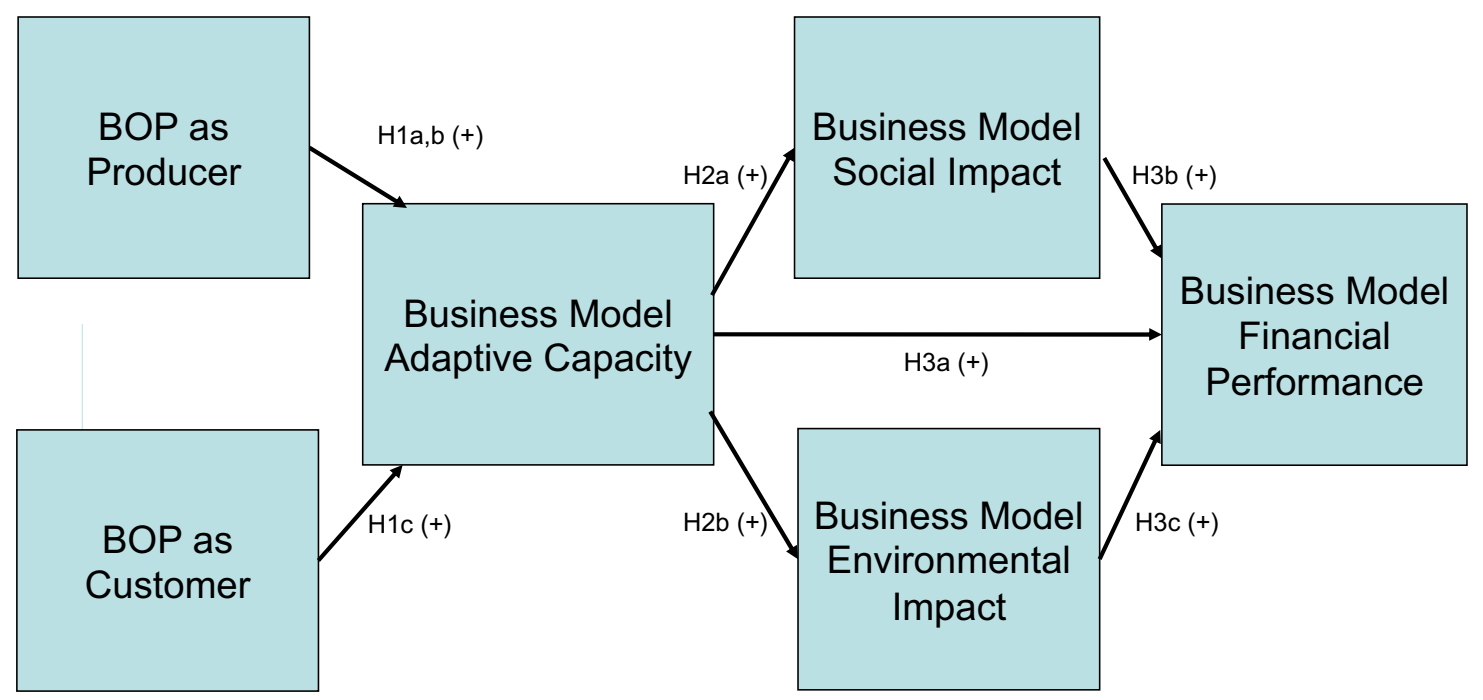

Fig. 1 Theoretical assumptions underlying a sustainable BOP approach 
interrater agreement score (James et al., 1993) and found a median interrater agreement $\left(r_{\mathrm{wg}}\right)$ between 0.62 and 0.92 suggesting adequate agreement. Moreover, the intraclass correlations suggest strong interrater reliability with correlations significant at the 0.001 level. To evaluate social and environmental impact, we surveyed one manufacturing plant and measured estimated impact as perceived by 12 managers and 9 employee-community members. The interrater agreement between the employee-community members was 0.90 and between the managers was 0.76 . The interrater agreement for the combined group as a whole was 0.87 indicating a high level of agreement between the managers and the employee-community members with respect to their assessment of the social and environmental impact of the organization.

Although complex models are less likely to suffer from common method bias (Chang et al., 2010), we next examined whether the common method bias might have influenced the relationships in our study. We performed Harman's one-factor test (Fuller et al., 2016) and rejected the hypothesis that one general factor would underlie the relationships $(p<0.01)$. We constructed a marker variable (Podsakoff et al., 2003) and found that the average correlation between the marker and the principal variables of our study was very small ( $r=0.01$; average $p=0.47$ ). The results of these analyses suggest that common method bias is unlikely to have substantially influenced our relationships.

\section{Triple Bottom Line: Social Impact, Environmental Impact, and Financial Performance}

In the past, the triple-bottom-line approach has been criticized due to its lack of reliable measurements (Norman \& MacDonald, 2004; Pava, 2007). We used formative scales (see Table 1) to measure the firm's multidimensional social, environmental, and financial performance (Jarvis et al., 2003). For social impact, we adapted 16 items from the AtKisson Compass and the Dow Jones Sustainability Group Index (Atkisson \& Hatcher, 2001). For environmental impact, we adapted ten items from the Environmental Sustainability Index and the AtKisson Compass (Esty et al., 2005). Following Ramanujam et al. (1986), we measured financial performance using seven items that measure multiple dimensions of financial performance. All items are measured on a seven-point agreement scale. We include both direct and indirect impact in the measure of the social and environmental impact and excluded the impact of philanthropic activities.

Following Hair et al. (2017a; Hair et al., 2017b), we applied an extensive procedure to validate the formative measures. In the first phase, we evaluated the content validity of the items using a review of the literature and the expert opinion of seven experienced managers at the
BOP (Jarvis et al., 2003). The expert opinions indicate that the list of items considers the important aspects of the constructs. In the second phase, we assessed the convergent validity of the scales using single item measures (Sarstedt et al., 2013) for social impact (the extent to which the organization acts in socially responsible ways) and environmental impact (the extent to which the organization acts in environmentally responsible ways) and for financial performance (the overall financial performance of the organization). The $R^{2}$ of the three formative constructs with the single items vary between 0.659 and 0.738 , which is well above the threshold mentioned in the literature (Hair et al., 2017a, b, p. 162).

In the third phase, we evaluated the redundance of the items that may cause problematic collinearity in the formative constructs (Hair et al., 2017a, b). Problematic collinearity occurs if the items of formative constructs have variance inflation factor (VIF) scores of five or higher (Hair et al., 2011). The VIF scores of the items of social impact were between 1.577 and 2.791, environmental impact between 1.497 and 2.258, and financial performance between 1.817 and 3.638. Thus, we conclude that the items of our measures do not cause problematic collinearity.

In the final phase, we evaluated the relevance of each item by calculating its outer loading and outer weight (Hair et al., 2010). The outer weight is the standardized regression coefficient of the item with its latent formative construct. The outer weights indicate the contribution of the item to the formative latent construct. Formative items have a significant absolute contribution if the outer loadings are significantly different from zero; the items are a significant relative contribution if the outer weighs are significantly different from zero (Hair et al., 2017a, b). We calculated the outer loadings and outer weighs for each item and performed bootstrapping to produce 5000 samples. The average outer loadings and outer weighs of the 5000 samples are reported in Table 1.

All outer loadings and outer weighs are significant at a $p$ value of $1 \%$ indicating that both the absolute and the relative contribution of the items are significant. The three most influential social impact items are impact on discrimination, integrity of the legal system, and the availability of clear and correct information. The three most influential environmental impact items are amount of material, energy use, and water use. This suggests that firms at the BOP can be particularly important in improving the integrity and quality of institutions and in improving the efficiency in the use of scarce natural resources. Overall, this analysis shows that it is possible to measure the perception of the triple bottom line with satisfactory reliability and validity. 
Table 1 Items for the triple bottom line

\begin{tabular}{|c|c|c|c|}
\hline Construct & Item & Outer loading ${ }^{c}$ & Outer weight $^{c}$ \\
\hline \multirow[t]{16}{*}{ Social impact ${ }^{\mathrm{a}, \mathrm{d}}$} & 1. Impact on livable wages & 0.541 & 0.096 \\
\hline & 2. Impact on overall skill level & 0.541 & 0.096 \\
\hline & 3. Impact on overall employment & 0.541 & 0.100 \\
\hline & 4. Impact on health education & 0.500 & 0.111 \\
\hline & 5. Impact on the availability of qualitatively good healthcare services and products & 0.545 & 0.115 \\
\hline & 6. Impact on discrimination (e.g., in salary or gender) & 0.634 & 0.136 \\
\hline & $\begin{array}{l}\text { 7. Impact on the availability of primary life necessities (water, air, sanitation, utilities, } \\
\text { nutrition, clothing, etc.) }\end{array}$ & 0.537 & 0.121 \\
\hline & 8. Impact on the availability of qualitatively good (regular) education & 0.547 & 0.119 \\
\hline & 9. Impact on participation of people in political decision making & 0.494 & 0.125 \\
\hline & 10. Impact on the infrastructure (housing, transportation, communication) & 0.528 & 0.118 \\
\hline & 11. Impact on the integrity of the legal system within the community & 0.583 & 0.130 \\
\hline & 12. Impact on local entrepreneurship & 0.462 & 0.104 \\
\hline & $\begin{array}{l}\text { 13. Impact on human rights (respect for the dignity and worth of all human beings } \\
\text { and freedom from fear and want) }\end{array}$ & 0.537 & 0.123 \\
\hline & $\begin{array}{l}\text { 14. Impact on the availability of clear and correct information from government } \\
\text { agencies }\end{array}$ & 0.582 & 0.127 \\
\hline & 15. Impact on physical safety & 0.472 & 0.121 \\
\hline & $\begin{array}{l}\text { 16. Impact on resistance to natural disasters and climate change (e.g., hurricanes, } \\
\text { earthquakes, floods, and the longer-term impact of climate change) }\end{array}$ & 0.367 & 0.121 \\
\hline \multirow[t]{10}{*}{ Environmental impact ${ }^{\mathrm{a}, \mathrm{e}}$} & 1. Impact on the health of the terrestrial ecosystem, including its biodiversity & 0.766 & 0.177 \\
\hline & $\begin{array}{l}\text { 2. Impact on the health of the aquatic and marine ecosystem, including its biodiver- } \\
\text { sity }\end{array}$ & 0.710 & 0.161 \\
\hline & 3. Impact on air quality & 0.623 & 0.146 \\
\hline & 4. Impact on the amount of overall material use & 0.746 & 0.173 \\
\hline & 5. Impact on the amount of water use & 0.721 & 0.165 \\
\hline & 6. Impact on the amount of energy use within the value chain, including customers & 0.715 & 0.167 \\
\hline & 7. Impact on the use of sustainable and renewable energy sources & 0.551 & 0.136 \\
\hline & 8. Impact on the amount of toxic discharges to the environment & 0.602 & 0.142 \\
\hline & 9. Impact on population pressure & 0.461 & 0.111 \\
\hline & $\begin{array}{l}\text { 10. Impact on natural resource management (e.g., productivity overfishing; percent- } \\
\text { age of total forest area certified for sustainable management) }\end{array}$ & 0.569 & 0.136 \\
\hline \multirow[t]{7}{*}{ Financial performance $\mathrm{b}^{\mathrm{b}, \mathrm{f}}$} & 1. Profitability and return on investment & 0.852 & 0.194 \\
\hline & 2. Future prospects & 0.699 & 0.157 \\
\hline & 3. Sales growth & 0.792 & 0.179 \\
\hline & 4. Customer satisfaction & 0.648 & 0.146 \\
\hline & 5. Financial stability & 0.839 & 0.190 \\
\hline & 6. Return on capital employed & 0.828 & 0.188 \\
\hline & 7. Overall performance & 0.886 & 0.197 \\
\hline
\end{tabular}

a All items are measured on a seven-point scale ranging from 1 "large negative impact" to 7 "large positive impact." All levels of the scale had a description

${ }^{\mathrm{b}}$ All items are measured on a seven-point scale ranging from 1 "very poor" to 7 "outstanding." All levels of the scale had a description

${ }^{\mathrm{c}}$ All significant at $p<0.01$

${ }^{\mathrm{d}}$ Items adapted from Atkisson and Hatcher (2001)

${ }^{\mathrm{e}}$ Items adapted from Esty et al. (2005)

${ }^{\mathrm{f}}$ Items adapted from Ramanujam et al. (1986) 


\section{Measurement Model of Business Model Adaptive Capacity}

Based on the relevant literature, we adapted six items from existing scales on flexible business capabilities (Gibson \& Birkinshaw, 2004; Grewal \& Tansuhaj, 2001; Saini \& Johnson, 2005) to construct and measure business model adaptive capacity. We first applied exploratory factor analyses to these indicators of business model adaptive capacity using principal component analysis and varimax rotation. We analyzed all dimensions of each scale to assess if the factor structure satisfied the four criteria suggested previously (DeVellis, 2011). We removed one item that did not satisfy these criteria, which resulted in a pool of five items (see Table 2). Each of the remaining items was loaded on the latent reflective construct for which it was developed. We assessed the reliability or the internal consistency of the construct via the composite reliability (0.903). We calculated the outer loadings of the items to assess the divergent validity of the scale, and the average variance was extracted. The outer loadings were above the 0.7 threshold, and the average variance extracted was 0.651 , which is higher than the 0.5 threshold generally accepted in the literature (Baldwin, 2019; Hair et al., 2017a, b). Finally, to assess the discriminant validity, we applied the Fornell-Larcker criterion (1981) and compared the square root of AVE (0.807) with the highest correlation of any other construct (see Table 3 ). The large difference shows that the construct business model adaptive capacity shares more variance with its indicators than with any other construct in our study, which indicates adequate discriminant validity. Thus, given this variety of supportive indices, we conclude that the measurement model of business model adaptive capacity construct is acceptable.

\section{BOP Involvement}

We next measured the involvement of the BOP as producer with a dummy variable, i.e., the value is one if the local producer is from the BOP and zero if the producer is not from the BOP. The focus on the BOP as supplier and consumer are measured with five categories where zero is no involvement, one is between 0 and $49 \%$, two is $50 \%$, three is between 50 and $100 \%$, and four is $100 \%$ involvement.

\section{Control Variables}

We included measures to control for firm size, firm age, industry, alliance, and subsidiary relationship. Following Becker et al. (2016), we selected only control variables that are theoretically relevant for our proposed theoretical framework. Firm size, firm age, and industry may influence the nature and development of business model adaptive capacity. Larger and older organizations tend to accumulate a larger variety with size and age of the organization and the industry (Wright \& Snell, 1998). The adaptive capacity of subsidiary organizations and organizations with formal alliances may be lower because these organizations need approval for business model adaptation from the parent company or the alliance organization's headquarters (Michailova \& Zhan, 2015).

Firm size was measured with the number of employees in ten categories $(1=10-25,2=26-50,3=51-100$, $4=101-150,5=151-250,6=251-500,7=501-1000$, $8=1001-2000,9=2000-5000,10=5000->)$. We measured firm age by the number of years since the foundation of the organization. The industry of the respondents was measured with the North American Industry Classification System. We measured the subsidiary relationship with a dummy variable with the value one if the firm is majority owned by another corporation and zero otherwise. We measured alliance with a dummy variable with the value one if the firm is in a formal alliance or joint venture contract and otherwise is zero. Informal alliances are not included in this measure.

\section{Results}

Table 3 provides descriptive statistics of the variables. To estimate the full set of relationships, we performed structural equation modeling (SEM) with clustered standard errors.

Table 2 Measurement items and validity assessment of business model adaptive capacity

\begin{tabular}{ll}
\hline Composite reliability $=0.903$, Average variance extracted $=0.651$ & Factor loadings \\
\hline Our management systems encourage employees to challenge outmoded traditions/practices/sacred cows $^{\mathrm{a}}$ & 0.801 \\
Our business model is flexible enough to allow us to respond quickly to changes in our markets ${ }^{\mathrm{a}}$ & 0.817 \\
Our business model evolves rapidly in response to shifts in our business priorities ${ }^{\mathrm{a}}$ & 0.813 \\
It is difficult for our organization to change the uses and applications of its resources $^{\mathrm{b}}$ & 0.789 \\
Our strategy reflects a high level of flexibility in managing risks $^{\mathrm{c}}$ & 0.814 \\
\hline
\end{tabular}

${ }^{a}$ Item adapted from Gibson and Birkinshaw (2004)

${ }^{\mathrm{b}}$ Item adapted from Saini and Johnson (2005)

${ }^{\mathrm{c}}$ Item adapted from Grewal and Tansuhaj (2001) 


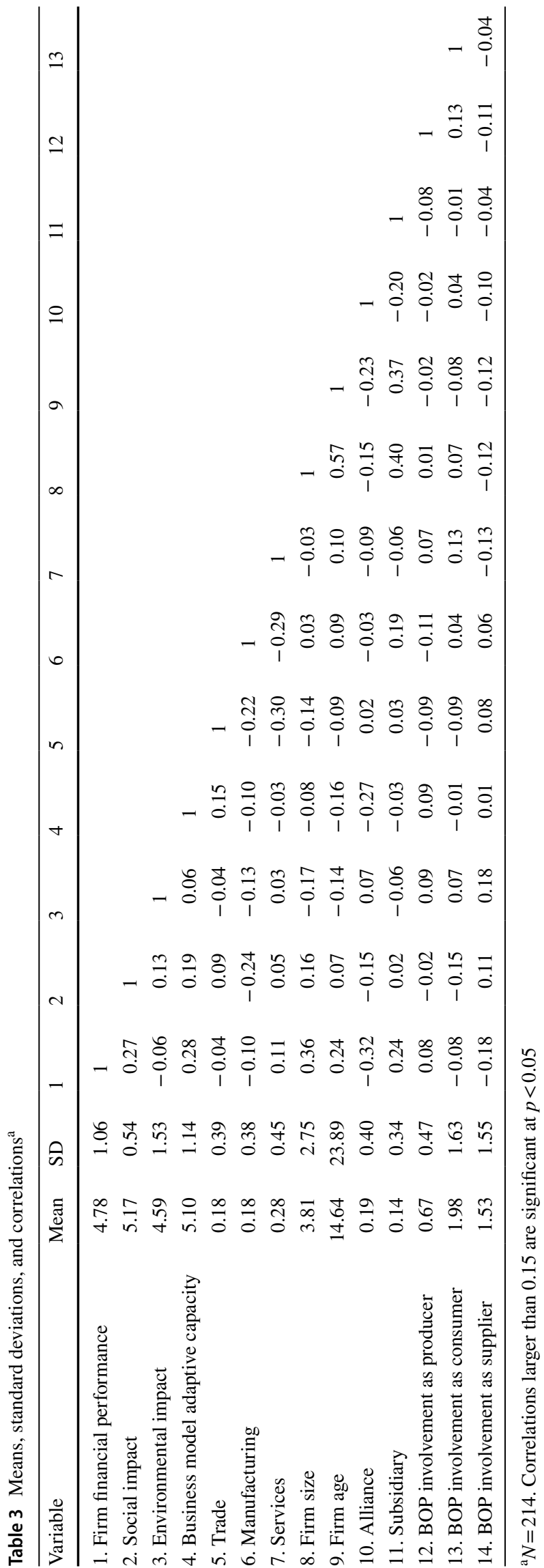

SEM is the appropriate estimation technique because it allows one to examine the full set of structural equations. In SEM, the dependent variable in one equation becomes an independent variable in another relationship. We used clustered standard errors because several unobserved variables related to the country conditions may influence the variables of our model (Cameron \& Miller, 2015). For example, if a country has strict social and environmental regulations and enforcement, then the relationship between social and environmental impact and financial performance may be stronger. SEM estimation with clustered standard errors can help to remove such influence of omitted variables related to the specific country context (Stapleton, 2006). Furthermore, we adjusted the firm's financial performance to the country average by dividing the financial performance by the average financial performance of the country, which makes financial performance independent from country-specific economic conditions.

Table 4 presents the results from the SEM using maximum likelihood estimation. We used SEM to estimate the full latent and structural model of our study. The measurement model obtained a satisfactory fit, and all remaining items have highly significant coefficients with the latent construct business model adaptive capacity. For the full Model 3, the CFI and TLI are 0.980 and 0.974 , respectively, which indicates a good fit. The RMSEA of 0.051 also supports a good model fit. The relationship between each indicator and its respective construct was statistically significant $(p<0.000)$; none of the confidence intervals held a negative sign supporting convergent validity (Baldwin, 2019; Hair et al., 1998).

In Table 4, Model 1 shows the results of the model with only social impact excluding the influence of environmental impact. Model 2 in Table 4 presents the results of a model with only environmental impact excluding the influence of social impact. In Table 4, Model 3 presents a full triplebottom-line model including both social and environmental impact. We used the full Model 3 in Table 4 to test the hypotheses.

In line with previous studies, we found that manufacturing firms, larger and older firms, and firms in an alliance have less adaptive capacity than other firms. The results of Model 3 in Table 4 support the positive influence of the BOP involvement as a producer $(\beta=0.055, p<0.01)$ and as a supplier $(\beta=0.107, p<0.01)$ on the adaptive capacity of the business model. These results support Hypotheses 1a and $1 \mathrm{~b}$ and indicate that involvement of BOP actors in the supply chain leads to a significant positive impact on business model adaptive capacity. In contrast to expectations, the involvement of the BOP as a consumer is negatively related to business model adaptive capacity and is highly significant $(\beta=-0.086, p<0.01)$. Hypothesis $1 \mathrm{c}$ is therefore not supported by the results. 
Table 4 Structural and measurement SEM model with clustered standard errors

\begin{tabular}{|c|c|c|c|c|c|c|}
\hline \multirow{3}{*}{$\begin{array}{l}\text { Estimated paths } \\
\text { Dependent variable: Firm financial performance }\end{array}$} & \multicolumn{2}{|l|}{ Model 1} & \multicolumn{2}{|l|}{ Model 2} & \multicolumn{2}{|l|}{ Model 3} \\
\hline & \multicolumn{2}{|c|}{ Social impact } & \multicolumn{2}{|c|}{ Environmental impact } & \multicolumn{2}{|c|}{ Combined impact } \\
\hline & Estimate & ( $p$ value $)$ & Estimate & $(p$ value $)$ & Estimate & ( $p$ value $)$ \\
\hline \multicolumn{7}{|l|}{ Path business model (BM) adaptive capacity } \\
\hline BOP as producer $\rightarrow$ BM adaptive capacity (H1a) & 0.055 & $(0.009)$ & 0.055 & $(0.009)$ & 0.055 & $(0.009)$ \\
\hline BOP as supplier $\rightarrow$ BM adaptive capacity (H1b) & 0.151 & $(0.028)$ & 0.151 & $(0.028)$ & 0.107 & $(0.005)$ \\
\hline BOP as customer $\rightarrow$ BM adaptive capacity (H1c) & -0.064 & $(0.000)$ & -0.063 & $(0.000)$ & -0.086 & $(0.001)$ \\
\hline Trade $\rightarrow$ BM adaptive capacity & -0.107 & $(0.102)$ & -0.103 & $(0.111)$ & -0.102 & $(0.095)$ \\
\hline Manufacturing $\rightarrow$ BM adaptive capacity & -0.104 & $(0.013)$ & -0.109 & $(0.012)$ & -0.118 & $(0.010)$ \\
\hline Services $\rightarrow$ BM adaptive capacity & -0.125 & $(0.089)$ & -0.125 & $(0.089)$ & -0.109 & $(0.102)$ \\
\hline Firm size $\rightarrow$ BM adaptive capacity & -0.040 & $(0.086)$ & -0.040 & $(0.082)$ & -0.041 & $(0.060)$ \\
\hline Firm age $\rightarrow$ BM adaptive capacity & -0.015 & $(0.056)$ & -0.014 & $(0.566)$ & -0.009 & $(0.694)$ \\
\hline Alliance $\rightarrow$ BM adaptive capacity & -0.107 & $(0.000)$ & -0.106 & $(0.000)$ & -0.104 & $(0.000)$ \\
\hline Subsidiary $\rightarrow$ BM adaptive capacity & -0.014 & $(0.580)$ & -0.014 & $(0.579)$ & -0.014 & $(0.628)$ \\
\hline \multicolumn{7}{|l|}{ Path social impact } \\
\hline BM adaptive capacity $\rightarrow$ social impact (H2a) & 0.653 & $(0.004)$ & & & 0.656 & $(0.004)$ \\
\hline \multicolumn{7}{|l|}{ Path environmental impact } \\
\hline $\mathrm{BM}$ adaptive capacity $\rightarrow$ environmental impact (H2b) & & & -0.030 & $(0.006)$ & -0.030 & $(0.006)$ \\
\hline \multicolumn{7}{|l|}{ Path firm financial performance } \\
\hline $\mathrm{BM}$ adaptive capacity $\rightarrow$ firm financial performance $(\mathrm{H} 2 \mathrm{c})$ & 0.688 & $(0.003)$ & 0.776 & $(0.000)$ & 0.695 & $(0.002)$ \\
\hline Social impact $\rightarrow$ firm financial performance (H3a) & 0.143 & $(0.034)$ & & & 0.140 & $(0.035)$ \\
\hline Environmental impact $\rightarrow$ firm financial performance (H3b) & & & 0.063 & $(0.020)$ & 0.060 & $(0.030)$ \\
\hline Trade $\rightarrow$ firm financial performance & 0.001 & $(0.985)$ & -0.002 & $(0.976)$ & -0.001 & $(0.988)$ \\
\hline Manufacturing $\rightarrow$ firm financial performance & -0.017 & $(0.706)$ & -0.010 & $(0.820)$ & -0.017 & $(0.699)$ \\
\hline Services $\rightarrow$ firm financial performance & 0.018 & $(0.605)$ & 0.021 & $(0.553)$ & 0.017 & $(0.615)$ \\
\hline Firm size $\rightarrow$ firm financial performance & 0.036 & $(0.522)$ & 0.053 & $(0.301)$ & 0.036 & $(0.515)$ \\
\hline Firm age $\rightarrow$ firm financial performance & 0.081 & $(0.272)$ & 0.083 & $(0.254)$ & 0.085 & $(0.254)$ \\
\hline Alliance $\rightarrow$ firm financial performance & 0.030 & $(0.458)$ & 0.012 & $(0.764)$ & 0.022 & $(0.569)$ \\
\hline Subsidiary $\rightarrow$ firm financial performance & 0.036 & $(0.441)$ & 0.028 & $(0.532)$ & 0.029 & $(0.500)$ \\
\hline \multicolumn{7}{|l|}{$\begin{array}{l}\text { Measurement model }(\text { composite reliability }=0.903 \text {, average } \\
\text { variance extracted }=0.651)\end{array}$} \\
\hline$\lambda_{1} \rightarrow$ Latent construct BM adaptive capacity & 0.981 & $(0.000)$ & 0.981 & $(0.000)$ & 0.982 & $(0.000)$ \\
\hline$\lambda_{2} \rightarrow$ Latent construct BM adaptive capacity & 0.993 & $(0.000)$ & 0.993 & $(0.000)$ & 0.993 & $(0.000)$ \\
\hline$\lambda_{3} \rightarrow$ Latent construct BM adaptive capacity & 0.992 & $(0.000)$ & 0.993 & $(0.000)$ & 0.993 & $(0.000)$ \\
\hline$\lambda_{4} \rightarrow$ Latent construct BM adaptive capacity & 0.977 & $(0.000)$ & 0.977 & $(0.000)$ & 0.977 & $(0.000)$ \\
\hline$\lambda_{5} \rightarrow$ Latent construct BM adaptive capacity & 0.985 & $(0.000)$ & 0.985 & $(0.000)$ & 0.985 & $(0.000)$ \\
\hline \multicolumn{7}{|l|}{ Structural model fit } \\
\hline$R^{2}$ path $\mathrm{BM}$ adaptive capacity & 0.052 & & 0.042 & & 0.042 & \\
\hline$R^{2}$ path social impact & 0.425 & & & & 0.430 & \\
\hline$R^{2}$ path environmental impact & & 0.024 & & & 0.024 & \\
\hline$R^{2}$ path firm financial performance & 0.626 & & 0.609 & & 0.635 & \\
\hline \multicolumn{7}{|l|}{ Measurement model fit } \\
\hline RMSEA (root mean squared error of approximation) & 0.053 & & 0.053 & & 0.051 & \\
\hline CFI (comparative fit index) & 0.982 & & 0.983 & & 0.980 & \\
\hline TLI (Tucker-Lewis index) & 0.976 & & 0.977 & & 0.974 & \\
\hline
\end{tabular}

Our results show that business model adaptive capacity has a strong and highly significant impact on social impact ( $\beta=0.656, p<0.01$ ), which supports Hypothesis 2a. Business model adaptive capacity has a negative and significant impact on environmental impact $(\beta=-0.030, p<0.01)$. This result does not support Hypothesis $2 b$. Finally, we found a large and positive influence of business model adaptive capacity on financial performance $(\beta=0.695, p<0.01)$, 
which supports Hypothesis 2c. These results indicate that business model adaptive capacity supports social impact and financial performance, but it does not support positive environmental impact at the BOP. The evidence in Table 4 supports the positive impact of social $(\beta=0.140, p<0.05)$ and environmental impact $(\beta=0.060, p<0.05)$ on financial performance, which supports Hypotheses $3 \mathrm{a}$ and $3 \mathrm{~b}$.

$\mathrm{n}$ terms of $\mathrm{r}$, Cohen suggested corresponding.

figures of $0.10,0.30$, and 0.50 .

\section{Robustness Checks and Effect Sizes}

We tested the robustness and validity of our estimated model in several ways. First, we repeated the analyses by using different sets of items of social impact, environmental impact, and financial performance. We found no differences in the results. Second, we analyzed the impact of influential observations based on studentized residuals. Third, we performed a truncated regression to identify potential bias introduced by sampling on the dependent variable (Maddala 1986). Fourth, we performed a group invariance test on the results by taking the country with the most observations in our dataset (Brazil) and compared it with the other countries. Although the coefficients and significance levels changed, the signs of the structural and measurement model did not change.

We calculated the effects sizes $(r)$ of the hypothesized relationships in our study to assess the substance of the relationships. The unconditional direct standardized coefficient can be used as effect size in SEM models (Durlak, 2009). Cohen (2013) proposed that an effect size $r$ of 0.10 should be considered a small effect size, $r$ of 0.30 is medium, and $r=0.50$ is large. Following Cohen's classification, the impact of the BOP as producer $(r=0.06)$, BOP as supplier $(r=0.10)$, and BOP as consumer $(r=-0.09)$, should be considered small. However, the effect of categorical variables often underestimate the real impact of the variable, and one should assess the unstandardized direct effect instead (Breaugh, 2003). The unstandardized effects are for the BOP as producer $(b=0.16)$, BOP as supplier $(b=0.18)$, and BOP as consumer $(b=-0.10)$, which suggest that the effect sizes are between small and medium. The impact of business model adaptive capacity on social impact $(r=0.67)$, and financial performance $(0.77)$ can be considered large while the impact on environmental performance should be considered small $(r=-0.05)$. Finally, the impact of social impact on financial performance $(r=0.22)$ is a small to medium effect size while the effect size of environmental impact on financial performance $(r=0.07)$ is small. Overall, we conclude that adaptive capacity is a substantial factor to explain the social impact and financial performance of the business model; BOP involvement has a modest effect on business model adaptive capacity.

\section{Discussion}

In this study we specified and tested the theoretical relationships underlying the sustainable BOP approach. Specifically, we asked if BOP business model involvement and adaptive capacity of companies that simultaneously pursue economic and development goals can contribute to the triple bottom line at the BOP. We used a sample of 212 firms operating at the BOP in 37 countries and estimated a SEM model using clustered standards errors (Cameron \& Miller, 2015; Stapleton, 2006). The evidence suggests that BOP business model involvement and adaptive capacity are significant drivers of the triple bottom line at the BOP. We also found that social and environmental impact positively influences financial performance, however, business model adaptive capacity does not guarantee an ecologically sustainable triple bottom line at the BOP.

Including the BOP actors in the business model may reduce selective exposure to the dominant influence of high-income markets. However, the effect sizes found in this study are modest. Managers may have a tendency for selective perception and rationalization (March \& Simon, 1993). This could explain why in practice the stimuli of the BOP business partners are not fully absorbed. Alternatively, managers may have other sources that provide similar information, and this may also moderate the importance of BOP involvement.

Our findings suggest that a focus on BOP customers does not increase business model adaptive capacity. This finding challenges Prahalad and Ramaswamy's (2004) assumption that co-creation with customers at the BOP will increase the level of customization towards the unique conditions of poverty. However, customer co-creation can also lead to more standardized products and services if customers have simple demands or limited technological knowledge (Gurău, 2009). Organizations from developed markets are inclined to invest in adaptive capacity to meet advanced costumer needs while BOP customers may prefer simple solutions that are less tailored to customer needs but can be offered at a lower price (Garrette \& Karnani, 2010). In such conditions, the outcome of the customer co-creation process may be that it shows that customers prefer a standardized rather than a customized offer. This does not mean that customer co-creation is not important because customer involvement provides the relevant marketing information needed for the standardization. Advanced business models in developed markets often aim to simultaneously achieve efficiency and a high level of adaptation to customer needs (Adler, Goldoftas, \& Levine, 1999). However, this combination requires a high-quality information infrastructure that is often lacking at the BOP (Monteiro \& Macdonald, 1996). Managers at the BOP may 
face a difficult challenge to develop and implement ambidextrous business models that manage the tension between efficiency and customization in an information-poor environment (Reficco \& Gutiérrez, 2016). Our findings suggest that one way to solve this tension is to combine high adaptive capacity on the supply side in cooperation with the poor as business partner with high standardization of the demand side of the business model in cooperation with the poor as customers.

Our findings suggest that business model adaptive capacity is successful in creating social and financial value but not in creating positive environmental impact at the BOP. This suggests that for hybrid organizations adaptive capacity is not sufficient to achieve a balanced triple bottom line. Prior research suggested that adaptive capacity helps to accommodate the tension between competing social and commercial objectives (Smith \& Besharov, 2019). Our findings do not support this argument with respect to the environmental impact at the BOP. A critical gap in the hybrid organization literature is that it does not explain how hybrid organizations prioritize different objectives (Alexius \& Furusten, 2020; Denis et al., 2015). Consistent with corporate social sustainability research (Margolis \& Walsh, 2003), the BOP approach assumes that a win-win between the three elements of sustainable performance will lead to a sustainable performance. Our findings suggest that a win-win condition exists at the BOP between social, environmental and financial performance but this does not translate into positive environmental impact. One explanation of this finding is suggested by Baumgärtner et al. (2012). The authors argue that if managers have access to limited resources, then they allocate resources in a way that minimizes the opportunity costs of sustainable objectives. This means that even under win-win conditions, managers may not allocate their resources to a sustainable objective with higher opportunity costs. The results of our study indicate that the opportunity costs of environmental impact are more than twice as high than the opportunity costs of social impact at the BOP (see Model 3, Table 4). According to the trade-off analysis of Baumgärtner et al. (2012), this implies that organizations at the BOP may not prioritize the environmental elements of the triple bottom line.

Our findings are in line with warnings in the BOP literature that BOP communities tend to prioritize social impact over ecological impact (Duke, 2016). Local stakeholders tend to emphasize social impact at the BOP because social needs are more easily observable, take less time to materialize, and accrue more directly to individuals in BOP communities (Duke, 2016). Proponents of the BOP approach often assume that embeddedness with BOP communities internalizes ethical practices at the BOP (Lashitew et al., 2020). Firms benefit from the input of the actors at the BOP as a source of creativity and innovation (Hart \& Milstein, 2003, p. 63). However, our findings also suggest that this may lead to insufficient attention to environmental impacts. Given that environmental concerns are progressively increasing in significance (Wang \& Dong, 2019), corrective mechanisms such as ethical guidelines in the BOP protocol with respect to the ecological impact of the business model may need to be considered.

\section{Limitations and Future Research}

This study does have some limitations. First, our results only apply to hybrid BOP projects that simultaneously try to achieve economic and development objectives and, thus, cannot be generalized to BOP projects that only seek profitability. The original BOP 1.0 approach rejected ethical motivation and CSR of BOP projects because this would weaken the alignment with the core business competencies of the firm (Prahalad, 2005; Simanis \& Milstein, 2012), and these core competencies are an important basis for the expected positive externalities for the poor. Prior research did not produce evidence for these assumed positive externalities (Dembek et al. 2019). We found support for the argument that firms that simultaneously pursue development and profit goals may succeed to produce positive social outcomes for the poor; however, we did not find evidence that the sustainable BOP approach leads to positive environmental impact at the BOP. It is possible that just-for-profit firms would be able to realize lower opportunity costs for investments in environmental impact. For example, including the BOP as producer may also weaken the business capabilities to increase environmental impact because the $\mathrm{BOP}$ as producer often has less advanced environmental capabilities. Future research could try to explore such possibilities in the context of just-for-profit BOP solutions.

Our data are also based on perceptions from senior managers (or directors/owners). A strong interrater agreement and reliability with local community employees reduced our concern that these responses are biased; however, we cannot exclude that possibility that these perceptions differ from other stakeholder groups. Future research could include other stakeholder groups to assess the agreement among stakeholders regarding the triple bottom line of the organizations.

Third, financial performance is conceptualized and measured in this cross-sectional study as short-term financial performance. Further research may explore relationships of business model qualities that include long-term financial performance and survival of organizations at the BOP.

Finally, we did not include the cultural impact of the business model as a separate element of the triple bottom line. The impact on aspects such as language, religion, traditions, customs, arts, and crafts is an important aspect of sustainable development as defined by the BOP 3.0 approach (Cañeque 
\& Hart, 2015). However, a lack of agreement on the definition of culture and how to measure cultural impact stands in the way of the development of a quantitative assessment (Partal \& Dunphy, 2016). There is, however, good reason to include cultural impact because culture is an important component of well-being, and the lack of attention to culture seems to be an important cause of failure of business ventures at the BOP (Partal \& Dunphy, 2016). Future research may enrich the BOP approach with definitions of culture and with the development of methods for cultural impact assessment at the BOP.

Funding Funding was provided by Erasmus Research Institute of Management.

\section{Declarations}

Conflict of interest The authors have no conflicts of interest to declare that are relevant to the content of this article.

Open Access This article is licensed under a Creative Commons Attribution 4.0 International License, which permits use, sharing, adaptation, distribution and reproduction in any medium or format, as long as you give appropriate credit to the original author(s) and the source, provide a link to the Creative Commons licence, and indicate if changes were made. The images or other third party material in this article are included in the article's Creative Commons licence, unless indicated otherwise in a credit line to the material. If material is not included in the article's Creative Commons licence and your intended use is not permitted by statutory regulation or exceeds the permitted use, you will need to obtain permission directly from the copyright holder. To view a copy of this licence, visit http://creativecommons.org/licenses/by/4.0/.

\section{References}

Adler, P. S., Goldoftas, B., \& Levine, D. I. (1999). Flexibility versus efficiency? A case study of model changeovers in the Toyota production system. Organization Science, 10(1), 43-68.

Alexius, S., \& Furusten, S. (2020). Enabling sustainable transformation: Hybrid organizations in early phases of path generation. Journal of Business Ethics, 165(3), 547-563.

Anderson, J., \& Markides, C. (2007). Strategic innovation at the base of the pyramid. MIT Sloan Management Review, 49(1), 83-88.

Armstrong, J. S., \& Overton, T. S. (1977). Estimating nonresponse bias in mail surveys. Journal of Marketing Research, 14(3), 396-402.

Arnold, D. G., \& Williams, L. H. (2012). The paradox at the base of the pyramid: Environmental sustainability and market-based poverty alleviation. International Journal of Technology Management, 60(1-2), 44-59.

Arora, S., \& Romijn, H. (2012). The empty rhetoric of poverty reduction at the base of the pyramid. Organization, 19(4), 481-505.

Atkisson, A., \& Hatcher, R. L. (2001). The compass index of sustainability: Prototype for a comprehensive sustainability information system. Journal of Environmental Assessment Policy and Management, 3(4), 509-532.

Austin, J., Márquez, P., Reficco, E., Berger, G., Fedato, C., Fischer, R., $\&$ Prado, A. (2007). Building new business value chains with low income sectors in Latin America. In Business solutions for the global poor: Creating economic and social value (pp. 193-206). Wiley.

Baldwin, S. A. (2019). Psychological statistics and psychometrics using Stata. Stata Press.

Battilana, J., \& Dorado, S. (2010). Building sustainable hybrid organizations: The case of commercial microfinance organizations. Academy of Management Journal, 53(6), 1419-1440.

Baumgärtner, S., Sievers-Glotzbach, S., Hoberg, N., Quaas, M. F., \& Stumpf, K. H. (2012). Economic analysis of trade-offs between justices. Intergenerational Justice Review, 1, 4-9.

Becker, T. E., Atinc, G., Breaugh, J. A., Carlson, K. D., Edwards, J. R., $\&$ Spector, P. E. (2016). Statistical control in correlational studies: 10 Essential recommendations for organizational researchers. Journal of Organizational Behavior, 37(2), 157-167.

Berger, R., Choi, C. J., \& Kim, J. B. (2011). Responsible leadership for multinational enterprises in bottom of pyramid countries: The knowledge of local managers. Journal of Business Ethics, 101(4), 553-561.

Breaugh, J. A. (2003). Effect size estimation: Factors to consider and mistakes to avoid. Journal of Management, 29(1), 79-97.

Calton, J. M., Werhane, P. H., Hartman, L. P., \& Bevan, D. (2013). Building partnerships to create social and economic value at the base of the global development pyramid. Journal of Business Ethics, 117(4), 721-733.

Cameron, A. C., \& Miller, D. L. (2015). A practitioner's guide to cluster-robust inference. Journal of Human Resources, 50(2), 317-372.

Cañeque, F. C., \& Hart, S. L. (2015). Base of the pyramid 3.0: Sustainable development through innovation and entrepreneurship. Routledge.

Chang, S.-J., Van Witteloostuijn, A., \& Eden, L. (2010). From the editors: Common method variance in international business research. Journal of International Business Studies, 41(2), 178-184.

Chliova, M., \& Ringov, D. (2017). Scaling impact: Template development and replication at the base of the pyramid. Academy of Management Perspectives, 31(1), 44-62.

Chmielewski, D. A., Dembek, K., \& Beckett, J. R. (2020). 'Business Unusual': Building BoP 3.0. Journal of Business Ethics, 161(1), 211-229.

Cohen, J. (2013). Statistical power analysis for the behavioral sciences. Academic.

Dawar, N. D. N., \& Chattopadhyay, A. (2002). Rethinking marketing programs for emerging markets. Long Range Planning, 35(5), 457-474.

Dembek, K., Sivasubramaniam, N., \& Chmielewski, D. A. (2020). A systematic review of the bottom/base of the pyramid literature: Cumulative evidence and future directions. Journal of Business Ethics, 165(3), 365-382.

Denis, J. L., Ferlie, E., \& Van Gestel, N. (2015). Understanding hybridity in public organizations. Public Administration, 93(2), 273-289.

DeVellis, R. (2011). Scale development: Theory and applications (Vol. XXVI). Sage Publications, Inc.

Duke, D. (2016). Why don't BOP ventures solve the environmental problems they initially set out to address? Organization and Environment, 29(4), 508-528.

Durlak, J. A. (2009). How to select, calculate, and interpret effect sizes. Journal of Pediatric Psychology, 34(9), 917-928.

Elkington, J. (1997). Cannibals with forks: The triple bottom line of 21 st century business. Oxford.

Esty, D. C., Levy, M., Srebotnjak, T., \& De Sherbinin, A. (2005). Environmental sustainability index: Benchmarking national environmental stewardship (pp 47-60). Yale Center for Environmental Law and Policy. 
Fornell, C., \& Larcker, D. F. (1981). Structural equation models with unobservable variables and measurement error: Algebra and statistics. Sage Publications.

Foster, C., \& Heeks, R. (2013). Innovation and scaling of ICT for the bottom-of-the-pyramid. Journal of Information Technology, 28(4), 296-315.

Fuller, C. M., Simmering, M. J., Atinc, G., Atinc, Y., \& Babin, B. J. (2016). Common methods variance detection in business research. Journal of Business Research, 69(8), 3192-3198.

Garrette, B., \& Karnani, A. (2010). Challenges in marketing socially useful goods to the poor. California Management Review, 52(4), 29-47.

Gibson, C., \& Birkinshaw, J. (2004). Contextual determinants of organizational ambidexterity. Academy of Management Journal, 47(2), 209-226.

Globerman, S., \& Shapiro, D. (2003). Governance infrastructure and US foreign direct investment. Journal of International Business Studies, 34(1), 19-39.

Grewal, R., \& Tansuhaj, P. (2001). Building organizational capabilities for managing economic crisis: The role of market orientation and strategic flexibility. Journal of Marketing, 65(2), 67-80.

Gurău, C. (2009). Marketing flexibility in the context of the servicedominant logic. The Marketing Review, 9(3), 185-197.

Gutiérrez, R., Márquez, P., \& Reficco, E. (2016). Configuration and development of alliance portfolios: A comparison of same-sector and cross-sector partnerships. Journal of Business Ethics, 135(1), $55-69$.

Habermas, J. (1990). Moral consciousness and communicative action. MIT Press.

Hahn, R. (2009). The ethical rational of business for the poor-Integrating the concepts bottom of the pyramid, sustainable development, and corporate citizenship. Journal of Business Ethics, 84(3), 313-324.

Hair, J. F., Black, W. C., Babin, B. J., \& Anderson, R. E. (2010). Multivariate data analysis: International version. Pearson.

Hair, J. F., Black, W. C., Babin, B. J., Anderson, R. E., \& Tatham, R. L. (1998). Multivariate data analysis (Vol. 5). Prentice Hall.

Hair, J. F., Hult, G. T. M., \& Christian, M. (2017a). A primer on partial least squares structural equation modeling (PLS-SEM). Sage.

Hair, J. F., Ringle, C. M., \& Sarstedt, M. (2011). PLS-SEM: Indeed a silver bullet. Journal of Marketing Theory and Practice, 19(2), 139-152.

Hair, J. F., Sarstedt, M., Ringle, C. M., \& Gudergan, S. P. (2017b). Advanced issues in partial least squares structural equation modeling. Sage Publications.

Halme, M., Lindeman, S., \& Linna, P. (2012). Innovation for inclusive business: Intrapreneurial bricolage in multinational corporations. Journal of Management Studies, 49(4), 743-784.

Hammond, A. L., Kramer, W. J., Katz, R. S., \& Tran, J. T. (2007). The next 4 billion: Market size and business strategy at the base of the pyramid. World Resources Institute.

Hart, S. L. (2005). Capitalism at the crossroads: The unlimited business opportunities in solving the world's most difficult problems. Pearson Education.

Hart, S. L., \& London, T. (2005). Developing native capability. Stanford Social Innovation Review, 3(2), 28-33.

Hart, S. L., \& Milstein, M. B. (2003). Creating sustainable value. Academy of Management Perspectives, 17(2), 56-67.

Immelt, J. R., Govindarajan, V., \& Trimble, C. (2009). How GE is disrupting itself. Harvard Business Review, 87(10), 56-65.

James, L. R., Demaree, R. G., \& Wolf, G. (1993). $\mathrm{r}_{\mathrm{wg}}$ : An assessment of within-group interrater agreement. Journal of Applied Psychology, 78(2), 306.

Jarvis, C. B., MacKenzie, S. B., \& Podsakoff, P. M. (2003). A critical review of construct indicators and measurement model misspecification in marketing and consumer research. Journal of Consumer Research, 30(2), 199-218.

Jenkins, C., \& Thomas, L. (2002). Foreign direct investment in Southern Africa: Determinants, characteristics and implications for economic growth and poverty alleviation. University of Oxford.

Jones, T. M. (1995). Instrumental stakeholder theory: A synthesis of ethics and economics. Academy of Management Review, 20(2), 404-437.

Karnani, A. (2007). Doing well by doing good—Case study: 'Fair \& Lovely' whitening cream. Strategic Management Journal, 28(13), 1351-1357.

Knorringa, P., Peša, I., Leliveld, A., \& Van Beers, C. (2016). Frugal innovation and development: Aides or adversaries? The European Journal of Development Research, 28(2), 143-153.

Lashitew, A. A., Bals, L., \& van Tulder, R. (2020). Inclusive business at the base of the pyramid: The role of embeddedness for enabling social innovations. Journal of Business Ethics, 162(2), 421-448.

Letelier, M. F., Flores, F., \& Spinosa, C. (2003). Developing productive customers in emerging markets. California Management Review, 45(4), 77-103.

London, T. (2016). The base of the pyramid promise: Building businesses with impact and scale. Stanford University Press.

London, T., \& Hart, S. (2011). Creating a fortune with the base of the pyramid. In Next generation business strategies for the base of the pyramid (pp. 1-18). Pearson Education.

Mair, J., Marti, I., \& Ventresca, M. J. (2012). Building inclusive markets in rural Bangladesh: How intermediaries work institutional voids. Academy of Management Journal, 55(4), 819-850.

March, H. A., \& Simon, J. G. (1993). Organizations. Blackwell.

Margolis, J. D., \& Walsh, J. P. (2003). Misery loves companies: Rethinking social initiatives by business. Administrative Science Quarterly, 48(2), 268-305.

Michailova, S., \& Zhan, W. (2015). Dynamic capabilities and innovation in MNC subsidiaries. Journal of World Business, 50(3), $576-583$

Monteiro, L., \& MacDonald, S. (1996). From efficiency to flexibility: The strategic use of information in the airline industry. The Journal of Strategic Information Systems, 5(3), 169-188.

Morgan, G. (1997). Images of organization. Sage Publications.

Nohria, N., \& Gulati, R. (1996). Is slack good or bad for innovation? Academy of Management Journal, 39(5), 1245-1264.

Nonaka, I. (1994). A dynamic theory of organizational knowledge creation. Organization Science, 5(1), 14-37.

Norman, W., \& MacDonald, C. (2004). Getting to the bottom of "triple bottom line." Business Ethics Quarterly, 14(2), 243-262.

Orlitzky, M., Schmidt, F. L., \& Rynes, S. L. (2003). Corporate social and financial performance: A meta-analysis. Organization Studies, 24(3), 403-441.

Parsons, T. (1964). Evolutionary universals in society. American Sociological Review, 29(3), 339-357.

Partal, A., \& Dunphy, K. (2016). Cultural impact assessment: A systematic literature review of current methods and practice around the world. Impact Assessment and Project Appraisal, 34(1), 1-13.

Pava, M. L. (2007). A response to "Getting to the Bottom of 'Triple Bottom Line.'” Business Ethics Quarterly, 17(1), 105-110.

Podsakoff, P. M., MacKenzie, S. B., Lee, J.-Y., \& Podsakoff, N. P. (2003). Common method biases in behavioral research: A critical review of the literature and recommended remedies. Journal of Applied Psychology, 88(5), 879-903.

Porter, M. E. (1995). Van der Linde (1995), Green and competitive: Ending the stalemate. Harvard Business Review, 73(5), 120-134.

Prahalad, C. (2009). The fortune at the bottom of the pyramid: Eradicating poverty through profits, revised and updated 5th anniversary edition. $\mathrm{PH}$ Professional Business.

Prahalad, C., \& Hart, S. (2002). The fortune at the bottom of the pyramid. Strategy + Business, 26, 2-14. 
Prahalad, C. K., \& Hammond, A. (2002). Serving the world's poor, profitably. Harvard Business Review, 80(9), 48-59.

Prahalad, C. K., \& Ramaswamy, V. (2004). Co-creation experiences: The next practice in value creation. Journal of Interactive Marketing, 18(3), 5-14.

Ramanujam, V., Venkatraman, N., \& Camillus, J. C. (1986). Multiobjective assessment of effectiveness of strategic planning: A discriminant analysis approach. Academy of Management Journal, 29(2), 347-372.

Reficco, E., \& Gutiérrez, R. (2016). Organizational ambidexterity and the elusive quest for successful implementation of BoP ventures. Organization and Environment, 29(4), 461-485.

Rosenstock, T. S., Lubberink, R., Gondwe, S., Manyise, T., \& Dentoni, D. (2020). Inclusive and adaptive business models for climate smart value creation. Current Opinion in Environmental Sustainability., 42, 76-81.

Saini, A., \& Johnson, J. L. (2005). Organizational capabilities in e-commerce: An empirical investigation of e-brokerage service providers. Journal of the Academy of Marketing Science, 33(3), 360-375.

Santos, N. J., \& Laczniak, G. R. (2009). Marketing to the poor: An integrative justice model for engaging impoverished market segments. Journal of Public Policy and Marketing, 28(1), 3-15.

Sarstedt, M., Wilczynski, P., \& Melewar, T. (2013). Measuring reputation in global markets-A comparison of reputation measures' convergent and criterion validities. Journal of World Business, 48(3), 329-339.

Simanis, E., \& Hart, S. (2008). The base of the pyramid protocol: Toward next generation BoP strategy (2nd ed., pp. 1-57). Cornell University.

Simanis, E., Hart, S., \& Duke, D. (2008). The base of the pyramid protocol: Beyond "basic needs" business strategies. Innovations: Technology, Governance, Globalization, 3(1), 57-84.

Simanis, E., \& Milstein, M. (2012). Back to business fundamentals: Making "bottom of the pyramid" relevant to core business. Field Actions Science Report, (Special Issue 4), 82-88.
Smith, W. K., \& Besharov, M. L. (2019). Bowing before dual gods: How structured flexibility sustains organizational hybridity. Administrative Science Quarterly, 64(1), 1-44.

Stapleton, L. M. (2006). Using multilevel structural equation modeling techniques with complex sample data. In Structural equation modeling: A second course (pp. 345-383). Information Age Publishing.

Sumner, A., Hoy, C., \& Ortiz-Juarez, E. (2020, April). Estimates of the impact of COVID-19 on global poverty (pp. 800-809). UNU-WIDER.

Sutter, C. J., Kistruck, G. M., \& Morris, S. (2014). Adaptations to knowledge templates in base-of-the-pyramid markets: The role of social interaction. Strategic Entrepreneurship Journal, 8(4), 303-320.

Tashman, P., \& Marano, V. (2009). Dynamic capabilities and base of the pyramid business strategies. Journal of Business Ethics, $89(4), 495-514$.

Teece, D. J. (2018). Business models and dynamic capabilities. Long Range Planning, 51(1), 40-49.

Wang, J., \& Dong, K. (2019). What drives environmental degradation? Evidence from 14 Sub-Saharan African countries. Science of the Total Environment, 656, 165-173.

Wright, P. M., \& Snell, S. A. (1998). Toward a unifying framework for exploring fit and flexibility in strategic human resource management. Academy of Management Review, 23(4), 756-772.

Publisher's Note Springer Nature remains neutral with regard to jurisdictional claims in published maps and institutional affiliations. 